Supplement of Biogeosciences, 12, 4067-4084, 2015

http://www.biogeosciences.net/12/4067/2015/

doi:10.5194/bg-12-4067-2015-supplement

(C) Author(s) 2015. CC Attribution 3.0 License.

(c) (1)

Supplement of

\title{
Investigating the usefulness of satellite-derived fluorescence data in infer- ring gross primary productivity within the carbon cycle data assimilation system
}

\section{E. N. Koffi et al.}

Correspondence to: E. N. Koffi (ernest.koffi@jrc.ec.europa.eu)

The copyright of individual parts of the supplement might differ from the CC-BY 3.0 licence. 


\section{Idealized tests with SCOPE}

Sensitivities of SIF and GPP to SCOPE parameters $\left(\mathrm{V}_{\mathrm{cmax}}, \mathrm{C}_{\mathrm{ab}}, \mathrm{R}_{\mathrm{in}}\right.$, aPAR). The results for $\mathrm{C} 4$ plant are mainly shown, otherwise specified. In fact, most of the results for C3 plant are shown in the paper. The SCOPE parameters used for these simulations are given in the Table 1 of the paper, otherwise specified in the graphs or their legends.

Fig. S1: Sensitivities of SCOPE SIF and GPP to $\mathrm{V}_{\mathrm{cmax}}$ for various values of aPAR and for C3 plant

Fig. S2: Effect of incoming short wave radiation on the SIF-Vcmax sensitivity and for C3 plant

Fig. S3a: Sensitivities of SCOPE SIF and GPP to $\mathrm{V}_{\mathrm{cmax}}, \mathrm{C}_{\mathrm{ab}}, \mathrm{R}_{\text {in }}$ and for $\mathrm{C} 4$ plant

Fig. S3b: As Fig.S1, but for C4 plant

Fig. S4: Sensitivities of SCOPE SIF and GPP to $\mathrm{V}_{\text {cmax }}$ for various values of $\mathrm{R}_{\text {in }}$ and aPAR and for C4 plant 


\section{C3 plant}

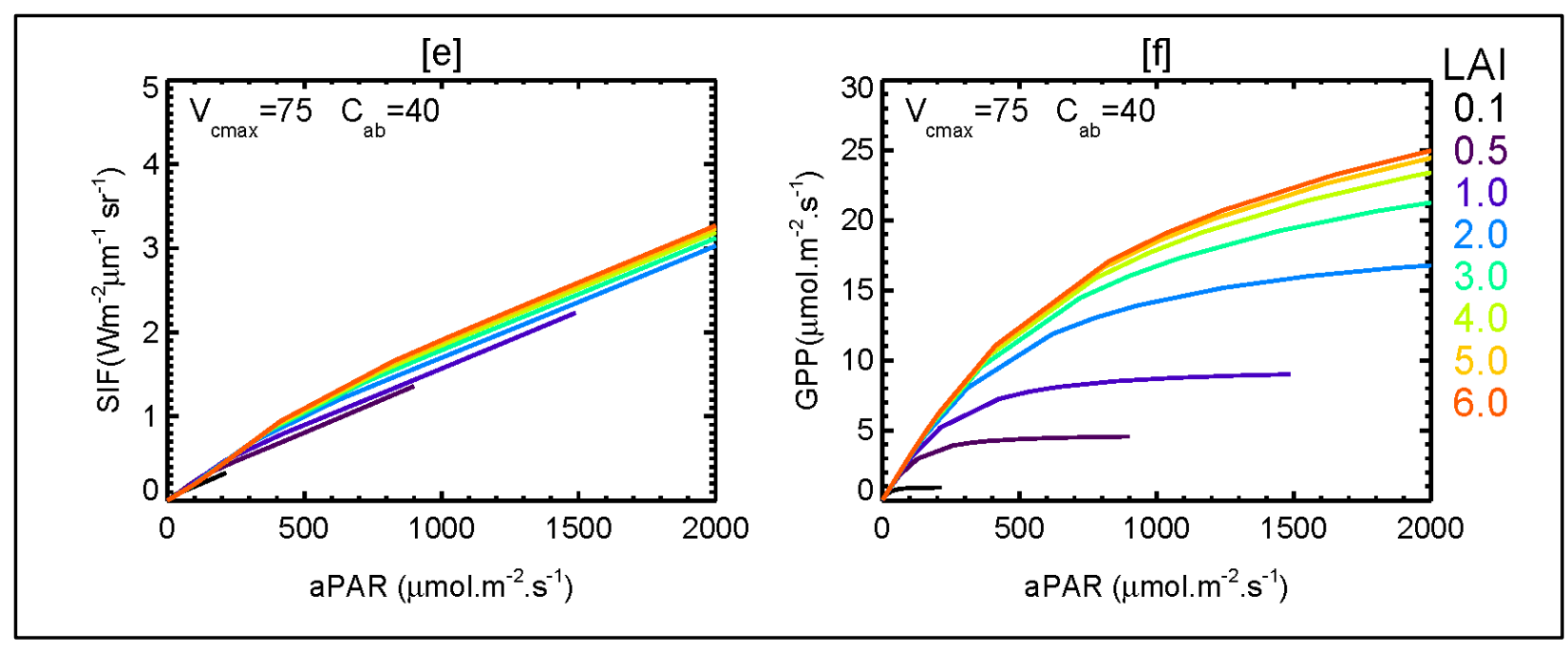

Fig. S1: The sensitivities of SCOPE fluorescence SIF (e) at the top of the canopy and GPP (f) of $\mathrm{C} 3$ plant to absorbed phtosynthetically active radiation (aPAR) for several leaf area indices (LAI) are shown. The LAI values are shown on right hand side of the graph f). SIF is computed at the frequency $755 \mathrm{~nm}$. 


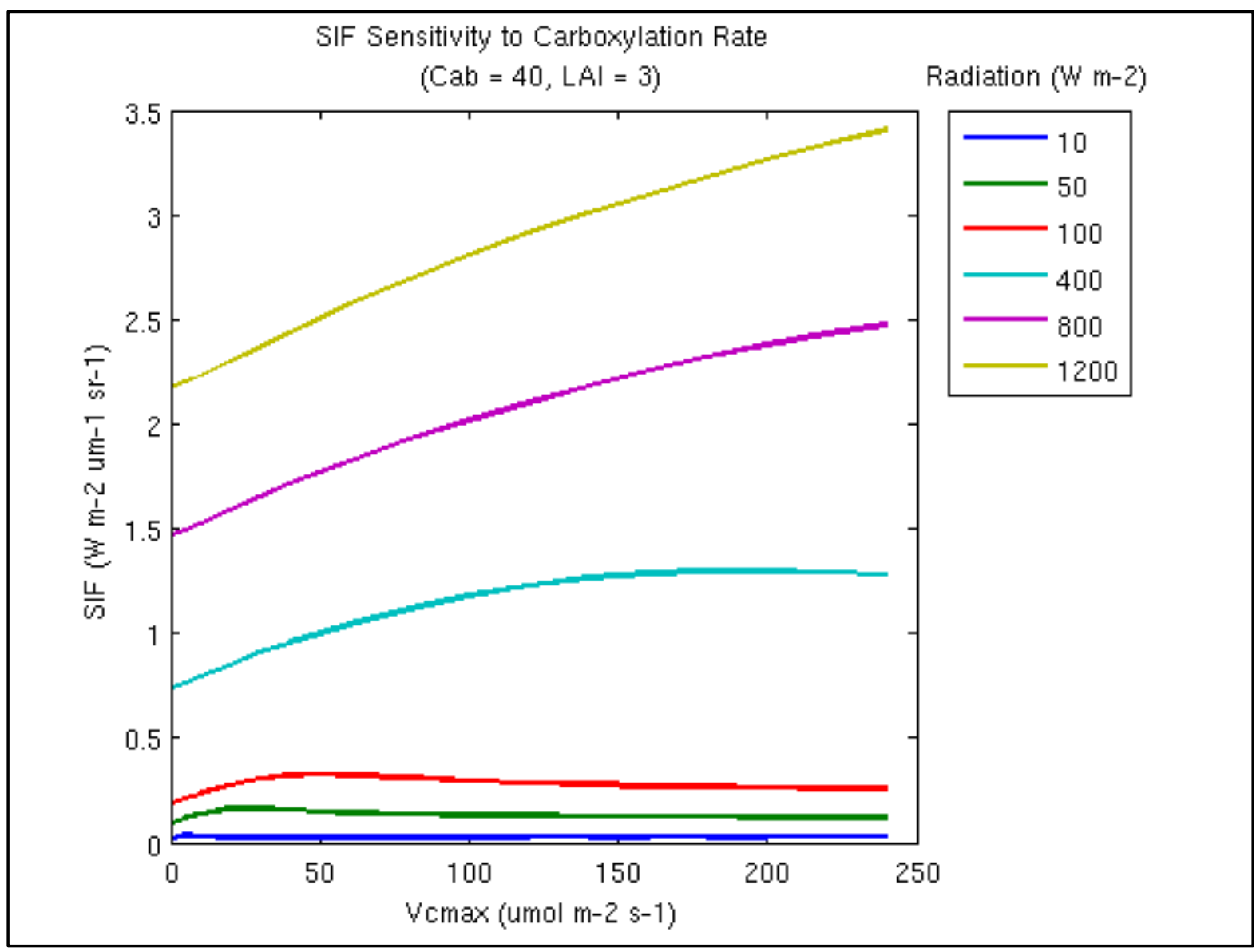

Fig. S2: Effect of incoming short wave radiation on the SIF- $\mathrm{V}_{\mathrm{cmax}}$ sensitivity and for C3 plant. SIF is computed at the frequency $755 \mathrm{~nm}$. 


\section{C4 plant}

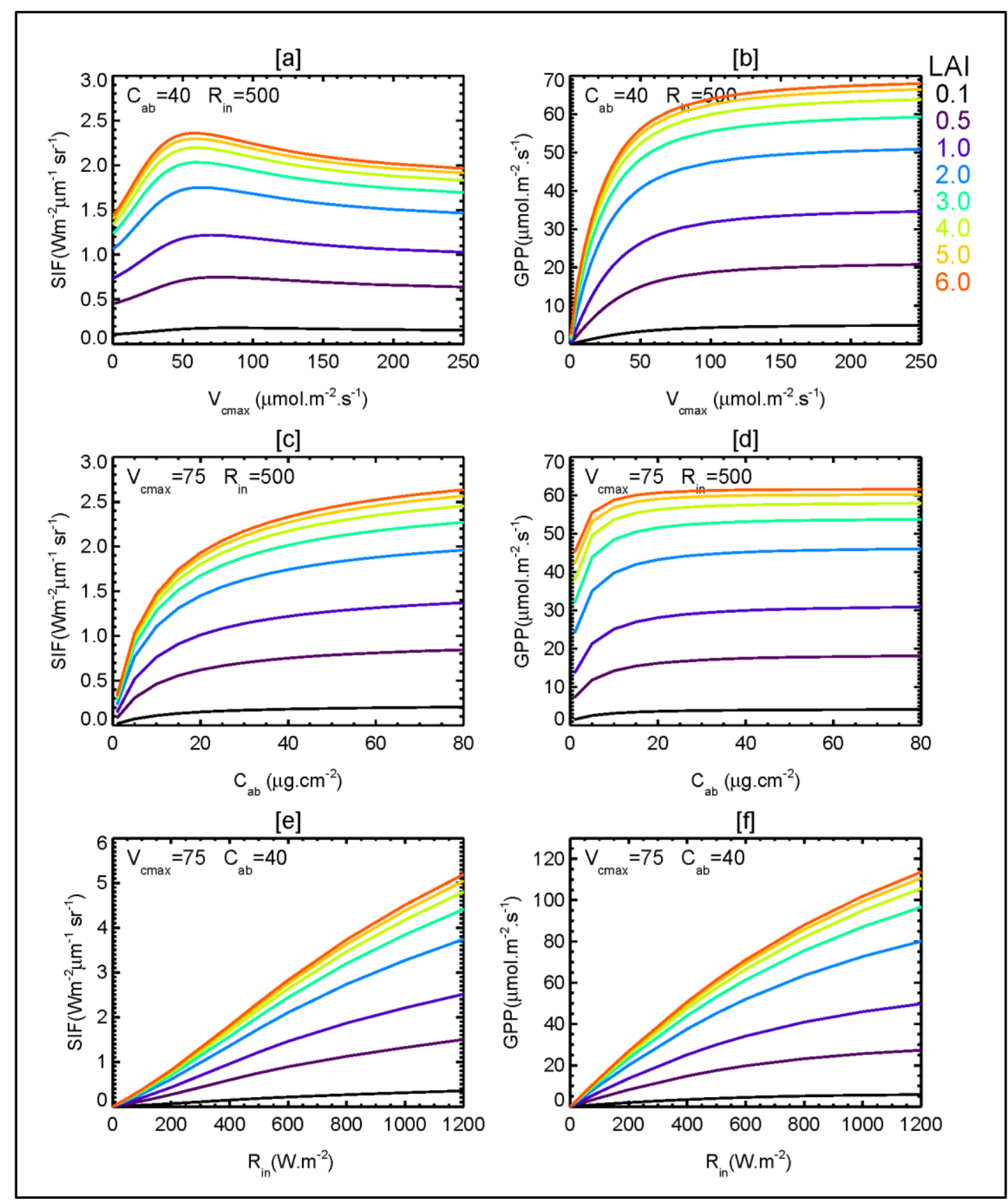

Fig. S3a: The sensitivities of SCOPE fluorescence (SIF) at the top of the canopy of C4 plant to the carboxylation maximum capacity $\left(\mathrm{V}_{\mathrm{cmax}}\right)$, chlorophyll $\mathrm{AB}$ content $\left(\mathrm{C}_{\mathrm{ab}}\right)$, and to broadband incoming shortwave radiation (0.4-2.5 $\mu \mathrm{m})\left(\mathrm{R}_{\text {in }}\right)$ for several leaf area indices (LAI) are shown. Graphs a) and b) stand for SIF and GPP as function of $V_{c m a x}$, respectively. The graphs c) and d) give the sensitivities of SIF and GPP to $\mathrm{C}_{\mathrm{ab}}$, respectively. The graphs e) and f) show SIF and GPP as a function of $R_{\text {in }}$, respectively. The LAI values are given on the top and the right hand side of the graph b). SIF is computed at the frequency $755 \mathrm{~nm}$. 


\section{C4 plant}

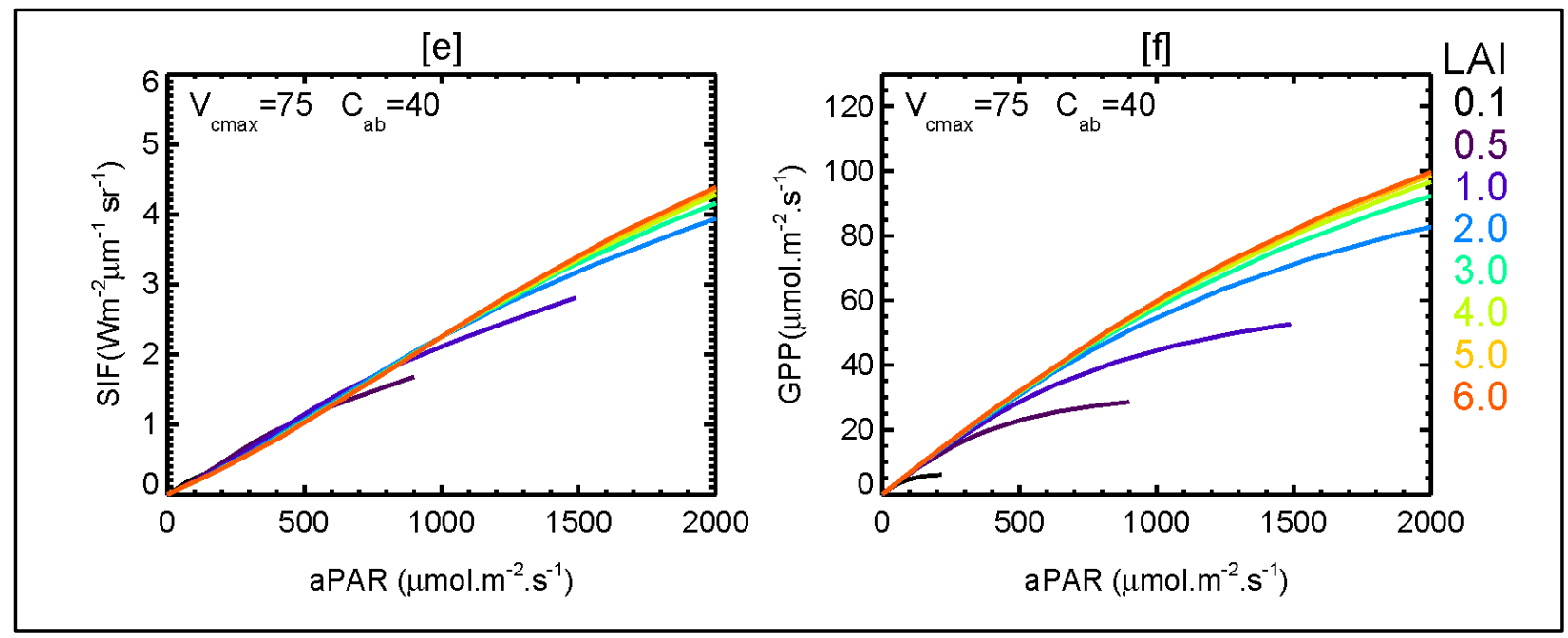

Fig. S3b: The sensitivities of SCOPE fluorescence SIF (e) at the top of the canopy and GPP (f) of $\mathrm{C} 4$ plant to absorbed phtosynthetically active radiation (aPAR) for several leaf area indices (LAI) are shown. The LAI values are given on right hand side of the graph f). SIF is computed at the frequency $755 \mathrm{~nm}$. 


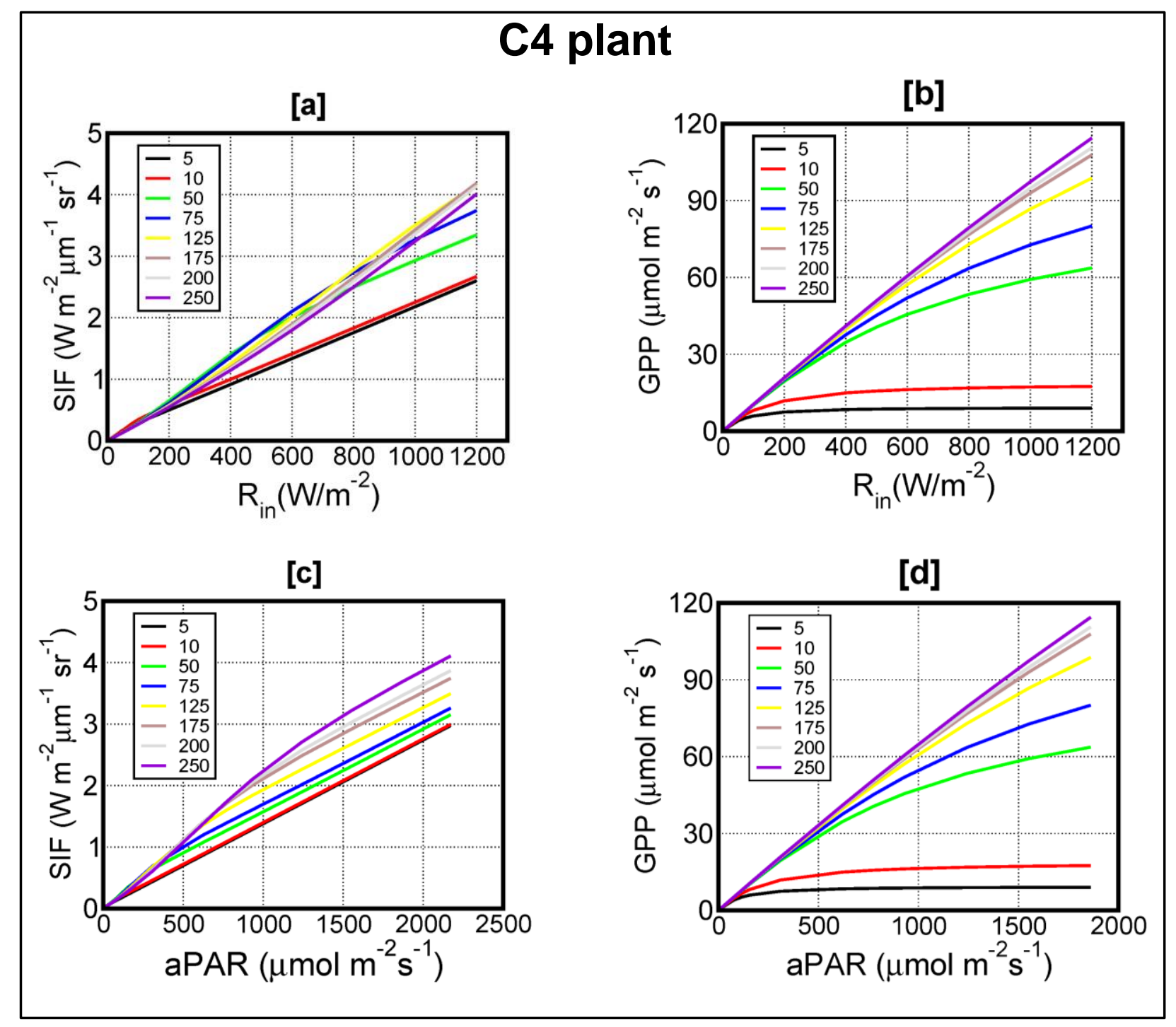

Fig. S4: The sensitivities of the SCOPE fluorescence SIF (a, c) and gross primary productivity (GPP) (b, d) to the incoming shortwave radiation $\left(\mathrm{R}_{\text {in }}\right)$ and absorbed phtosynthetically active radiation (aPAR) and for several $\mathrm{V}_{\text {cmax }}$ are presented. LAI is set to 2 . Results for a $\mathrm{C} 4$ plant are shown. The $\mathrm{V}_{\mathrm{cmax}}$ values are shown in each graph. SIF is computed at the frequency $755 \mathrm{~nm}$. 


\section{Comparison of SCOPE GPP simulations to FLUXNET data}

We made SCOPE simulations by using meteorological data (here temperature and incoming short wave radiation) observed at two FLUXNET stations (e.g., Baldocchi, 2003 and Papale et al., 2006; see the dedicated website: http://www.fluxnet.ornl.gov): Hyytiala (acronym FI-Hyy, longitude/latitude of $24.295^{\circ} / 61.847^{\circ}$ ) and Roccarespampani1 (acronym IT-Ro1 11.93/42.408). Unfortunately, we do not have any observed LAI data at these selected stations. We have then used the monthly LAIs of the biosphere model BETHY, which are relevant for the vegetation of the FLUXNET station. For this exercise, we keep constant the $\mathrm{V}_{\mathrm{cmax}}$. The $\mathrm{V}_{\mathrm{cmax}}$ values are from the BETHY PFTs as given in the Table 2 of the paper. We used two $\mathrm{V}_{\mathrm{cmax}}$ values: the prior and optimized values of Koffi et al. (2012). The relevant PFTs in BETHY for Hyytiala and Roccarespampanil are 5 and 9, respectively (Table 2). The modelled GPPs are compared against the FLUXNET ones. Note that SIF data are not measured at these stations for the period examined. As an illustration of the diurnal variations of both the simulated and observed GPP together with the input variables and also the simulated SIF at the station Hyytiala during summertime are shown in Figure 4 in the revised version of the paper. Another illustration of these diurnal variations during winter is shown in Fig. S5 for Roccarespampani1. Overall, results obtained from these two stations clearly show that SCOPE model can reproduce quite well the observed GPP with meaningful choices of both LAI and $\mathrm{V}_{\mathrm{cmax}}$ values (Figure 4 and Fig. S5).

The seasonal variations of these quantities are computed for some years at each of the two selected sites and shown in Figs. S6 and S7. The model reproduces quite well the observed GPP. However, the simulated SCOPE GPP peak over the year occurs earlier (within 1-2 months) than observed ones. This result is maybe caused by both LAI and $\mathrm{V}_{\mathrm{cmax}}$ of BETHY which seem apparently large during the growing season. Note that in these simulations, the LAIs are kept constant during a whole month and $\mathrm{V}_{\mathrm{cmax}}$ is set constant for each BETHY PFT. The results of these preliminary analyses can be then reinforced by using e.g., the satellite based MODIS weekly data relevant for these stations.

Finally, these graphs also show the weak sensitivity of SIF to $\mathrm{V}_{\mathrm{cmax}}$ and its relatively strong sensitivity to $\mathrm{C}_{\mathrm{ab}}$, especially under high light conditions. In contrary, SCOPE GPP is insensitive to $\mathrm{C}_{\mathrm{ab}}$, but strongly sensitive to $\mathrm{V}_{\mathrm{cmax}}($ Figs. $\mathbf{4}, \mathbf{S 5}, \mathbf{S 6}$, and $\mathrm{S7}$ ). 


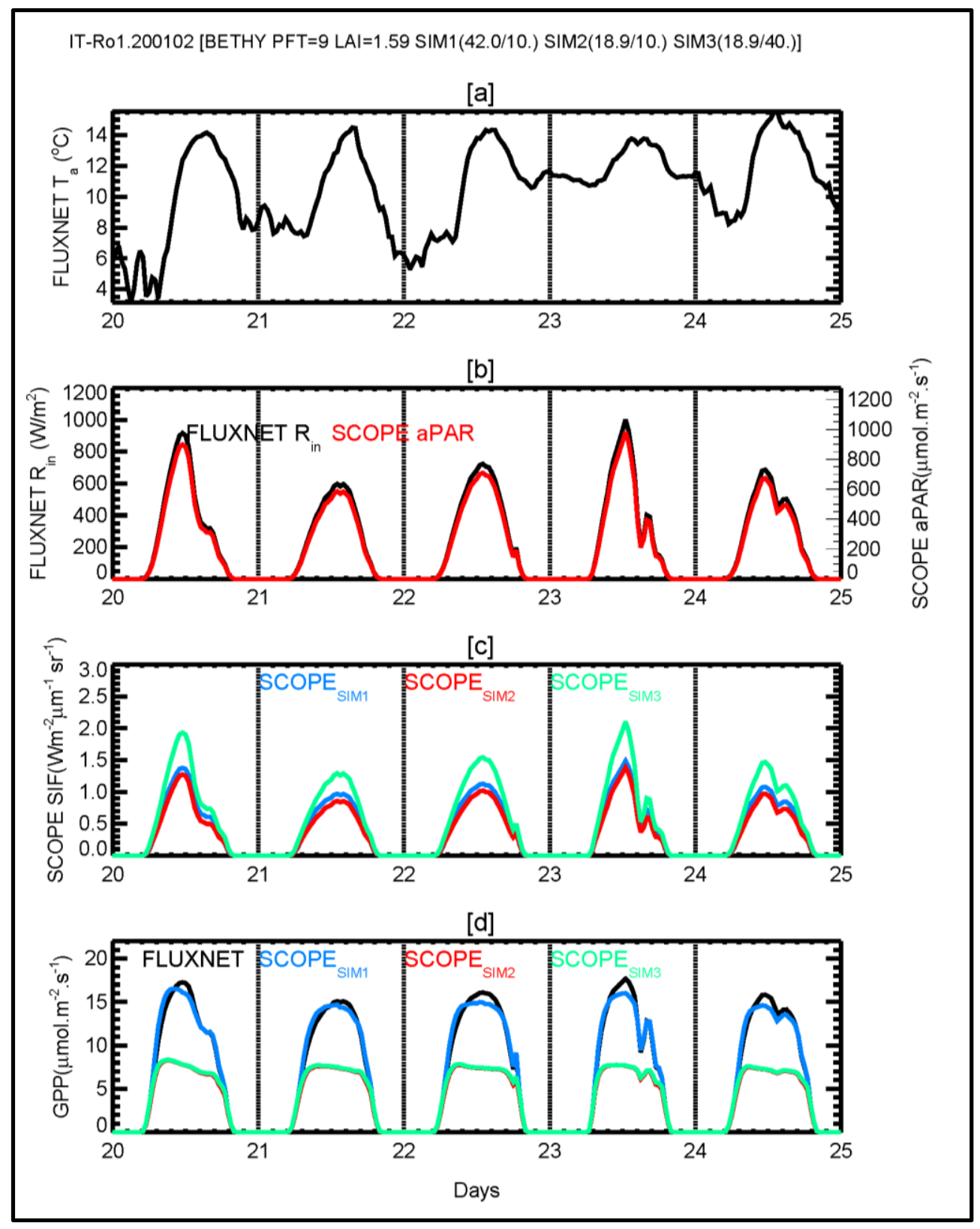

Fig. S5: SCOPE simulations of SIF, GPP, and aPAR from in situ measurements at Roccarespampani1 (acronym IT-Ro1 with longitude/latitude of 11.93/42.408) in Italy during 2001 over 20 to 25 February period. The graph a) presents the temporal variations of the observed temperature $\left(T_{a}\right)$. Graph $b$ ) shows the temporal variations of both observed incoming short wave radiation $\mathrm{R}_{\text {in }}$ (black) and SCOPE simulated aPAR (red). Graphs $\mathrm{c}$ and d) display the simulated SIF and GPP by using two values of both $\mathrm{V}_{\mathrm{cmax}}$ and $\mathrm{C}_{\mathrm{ab}}$ (blue: SCOPE $\mathrm{SIM}_{1}: \mathrm{V}_{\mathrm{cmax}} / \mathrm{C}_{\mathrm{ab}}$ $=42 \mu \mathrm{mol} \mathrm{m}^{-2} \mathrm{~s}^{-1} / 10 \mu \mathrm{g} \mathrm{cm}^{-2}$; red: SCOPE $\mathrm{SIM}_{2}$ : 18.9/10.; green: SCOPE $\mathrm{SIM}_{3}$ : 18.9/40.). The FLUXNET observed GPP is shown in graph d) and in black. The other SCOPE parameters are given in Table 1. The C3 plant is considered in SCOPE model. SIF is computed at the frequency $755 \mathrm{~nm}$. 
FI-Hyy.2001T2hh_bethy.txt [BETHY PFT=5 SIM1 (Vcmax/Cab: 29.0/10.) SIM2 (21.9/10.) SIM3 (21.9/40.)]
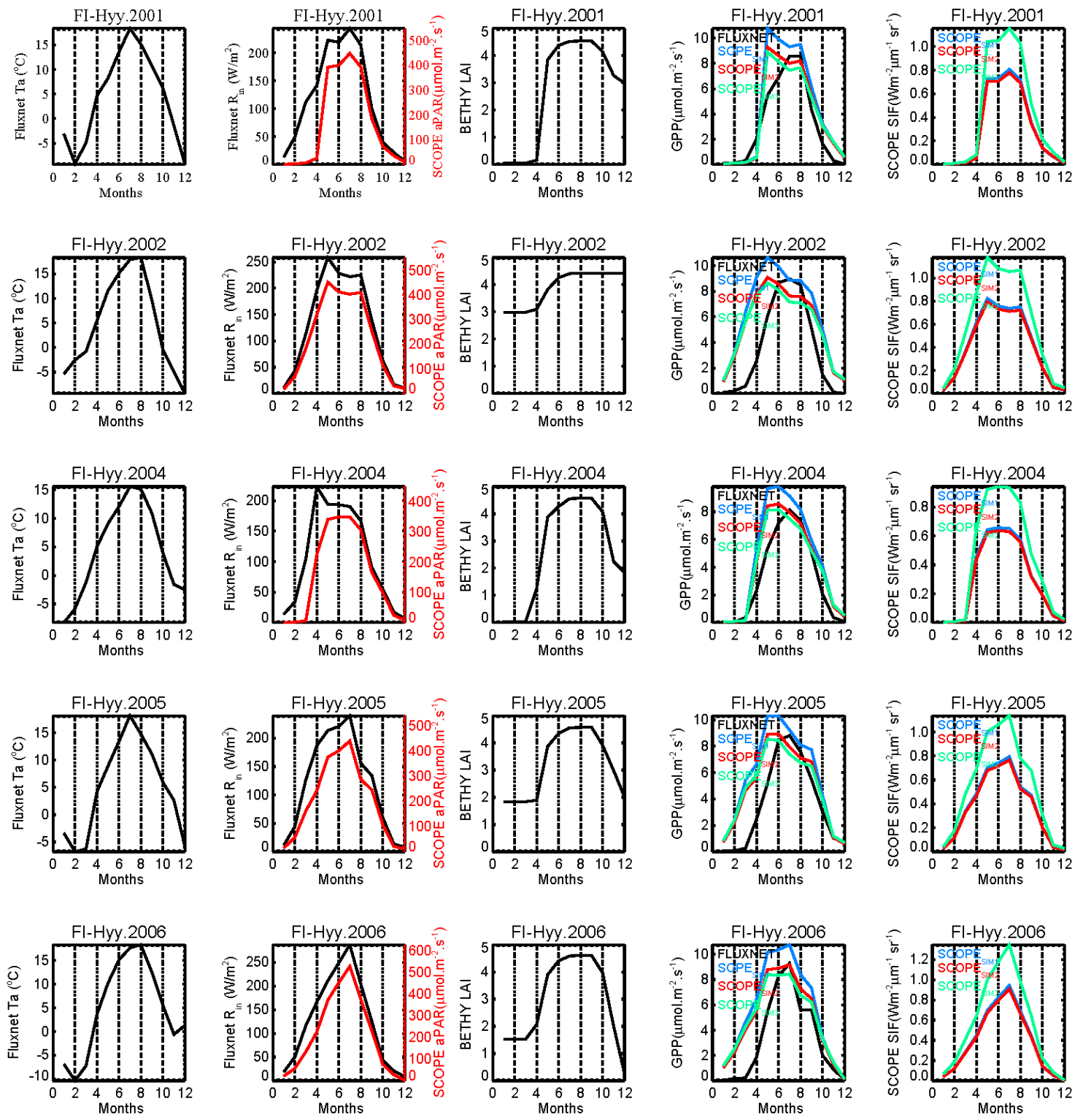

Fig. S6: Seasonal variations of FLUNET data (here temperature $T_{a}$, incoming short wave radiation at the top of the canopy $\mathrm{R}_{\mathrm{in}}$, and GPP) and SCOPE simulated quantities (aPAR, GPP, and SIF) at Hyytiala (acronym FI-Hyy and having longitude/latitude of $24.295^{\circ} / 61.847^{\circ}$ ) by using BETHY monthly LAI relevant to the vegetation of the station. The simulated SIF and GPP are performed by using two values of both $\mathrm{V}_{\mathrm{cmax}}$ and $\mathrm{C}_{\mathrm{ab}}$ (blue: $\mathrm{SCOPE}_{\mathrm{SIM} 1}: \mathrm{V}_{\mathrm{cmax}} / \mathrm{C}_{\mathrm{ab}}=29 \mu \mathrm{mol}$ $\mathrm{m}^{-2} \mathrm{~s}^{-1} / 10 \mu \mathrm{g} \mathrm{cm}^{-2}$; red: $\mathrm{SCOPE}_{\mathrm{SIM} 2}$ : 21.9/10; green: $\left.\mathrm{SCOPE}_{\mathrm{SIM} 3}: 21.9 / 40\right)$. The observations are in black and simulations in colors. SIF is computed at the frequency $755 \mathrm{~nm}$. 
IT-Ro1.2001T2hh_bethy.txt [BETHY PFT=9 SIM1 (Vcmax/Cab: 42.0/10.) SIM2 (18.9/10.) SIM3 (18.9/40.)]
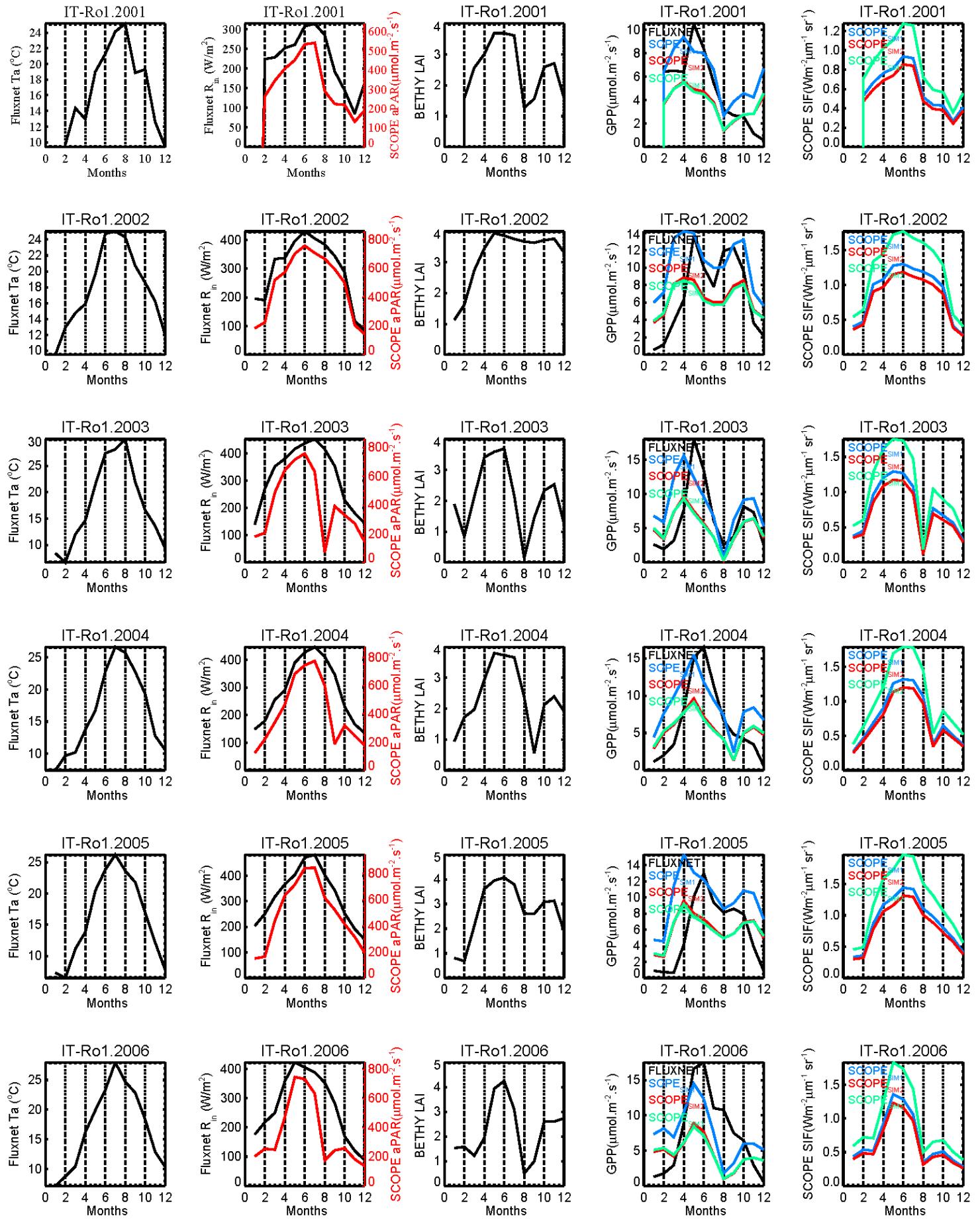

Fig. S7: As Fig. S6, but at Roccarespampani1 (acronym IT-Ro1) FLUXNET station. The values of $\mathrm{V}_{\mathrm{cmax}}$ and $\mathrm{C}_{\mathrm{ab}}$ for SCOPE simulations are given on the top of the graph 


\section{CCDAS simulations}

Fig. S8: Seasonal variations of the range of the incoming short wave radiation $\left(\mathrm{R}_{\text {in }}\right)$ used in the CCDAS simulations and for 2010 and at global and regional (southern hemisphere SH; Tropics; northern hemisphere $\mathrm{NH}$ ) are shown.

Fig. S9: Seasonal variations of SIF and aPAR for different regions of the globe

Fig. S10: Latitudinal distributions of SIF and aPAR 


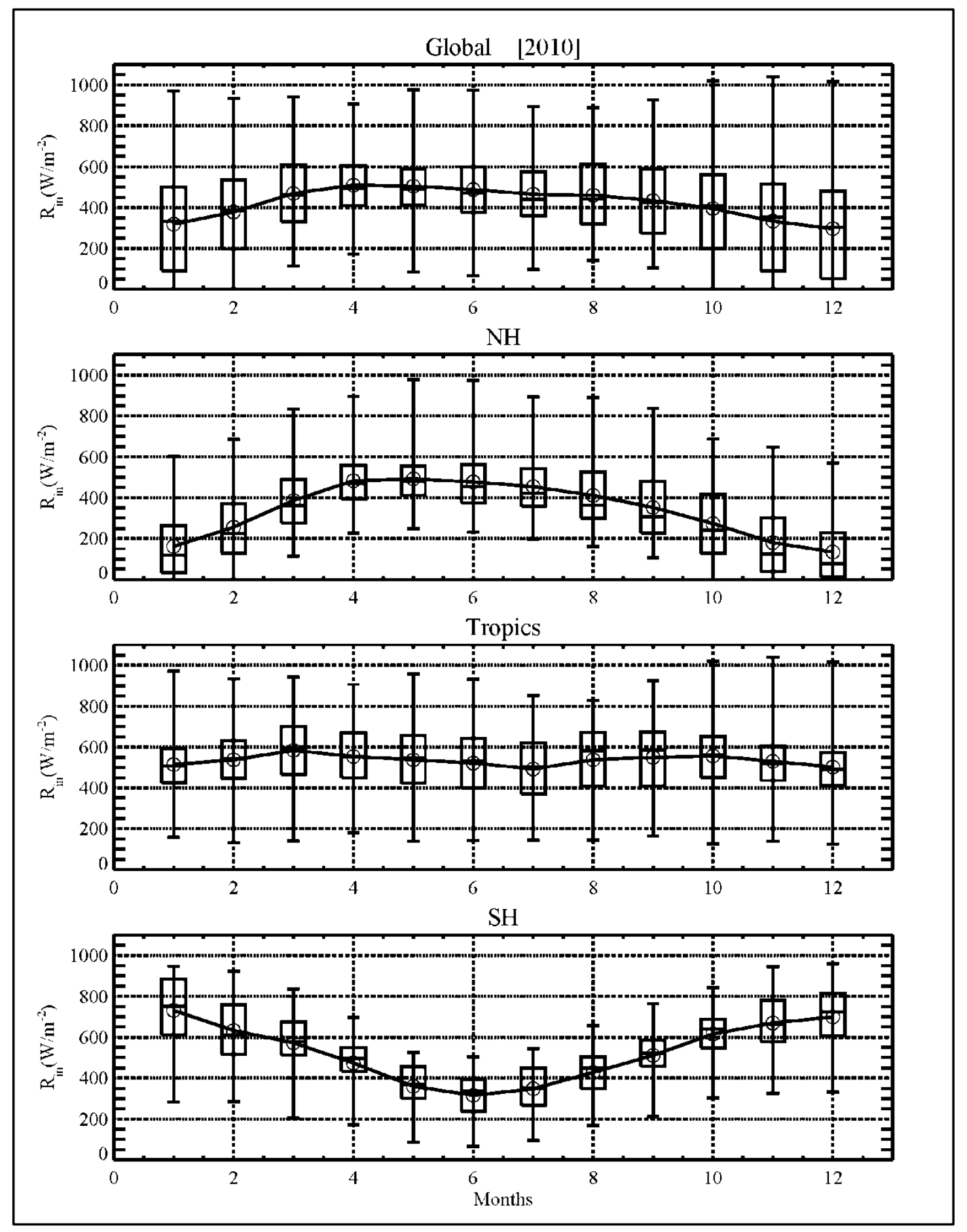

Fig. S8: Seasonal variations of the range of the incoming short wave radiation $\left(\mathrm{R}_{\text {in }}\right)$ used in the CCDAS simulations and for 2010 and at global and regional (Northern Hemisphere NH; Tropics; Southern Hemisphere $\mathrm{SH}$ ) scales are shown. The minimum and maximum values of $\mathrm{R}_{\text {in }}$ for each month are shown. The boxes are delimited by the $25 \%$ and $75 \%$ percentiles. The median values are given by the horizontal line in the boxes. The mean values are given by the open circles 


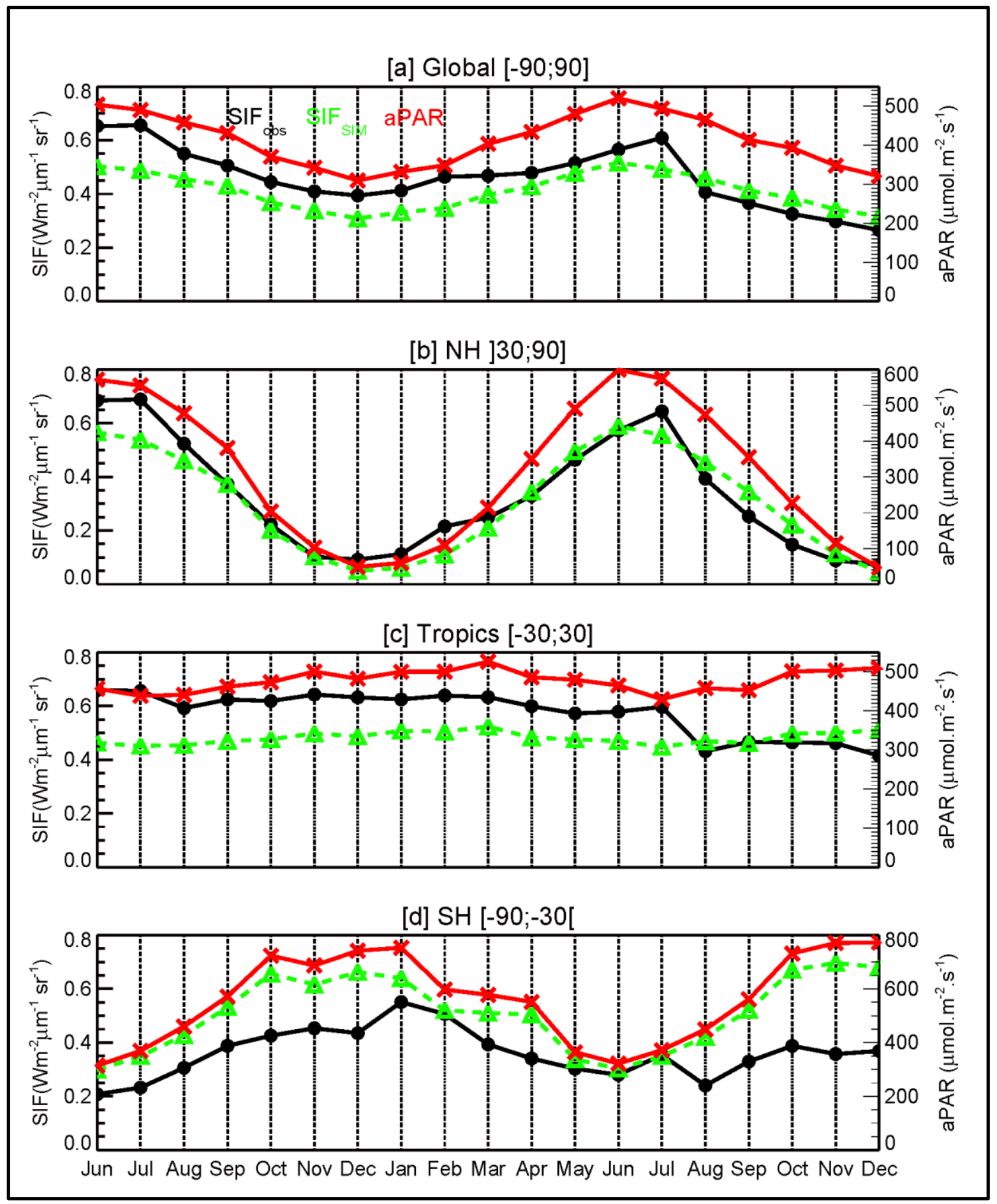

Fig. S9: Global (a) and regional (b to d) means of fluorescence SIF and absorbed phtosynthetically active radiation (aPAR) over June 2009 to December 2010 period are shown.

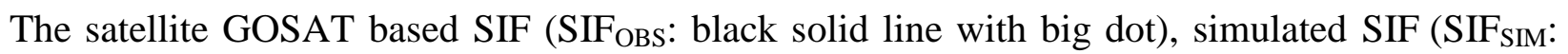
green dashed line with triangles), and the absorbed phtosynthetically active radiation (aPAR: red solid line with crosses) are displayed. The CCDAS set up S4 (Table 3) is considered. 


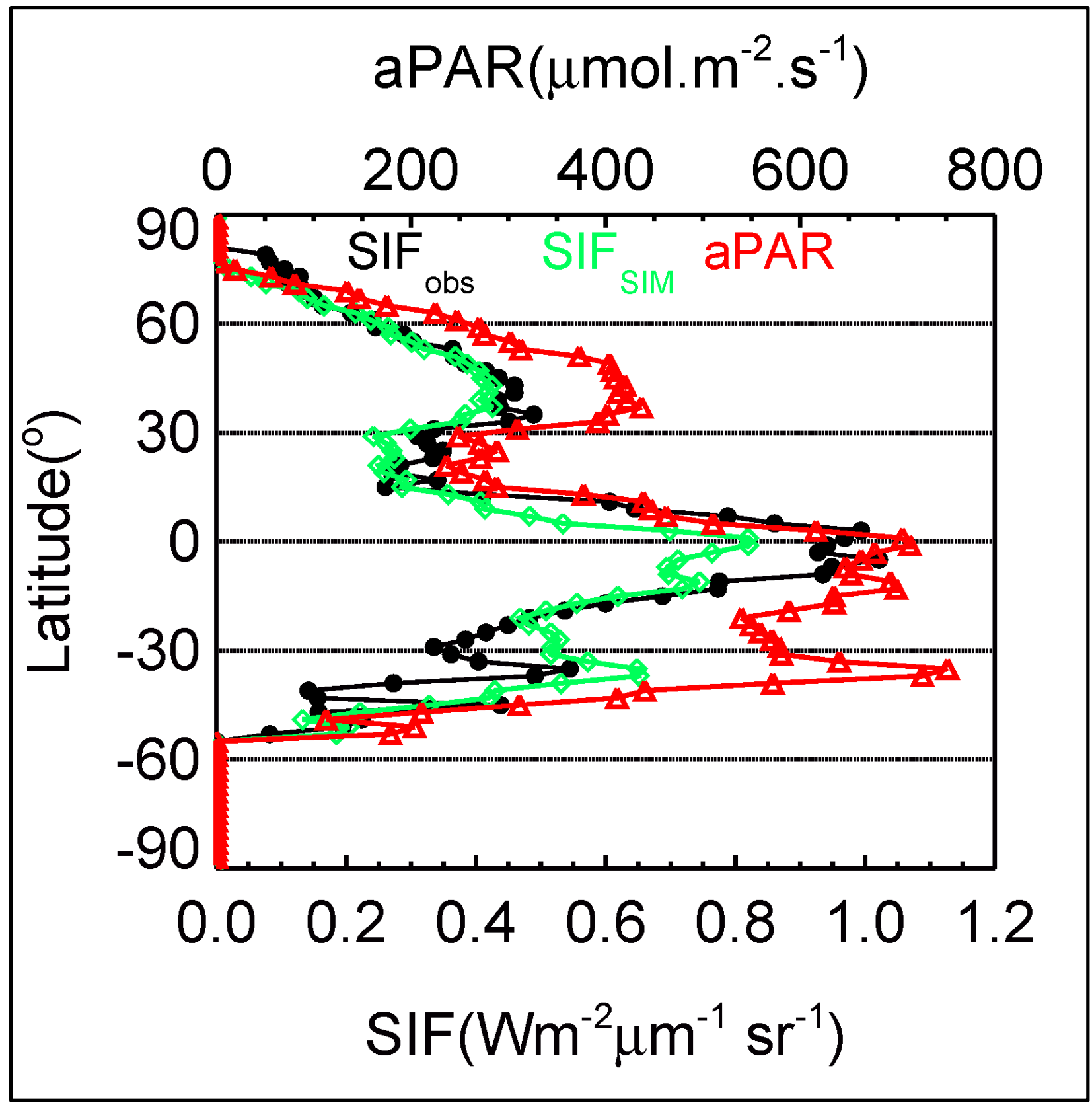

Fig. S10: Latitudinal distributions of the satellite GOSAT based SIF (SIF ${ }_{\mathrm{OBS}}$ : black solid line

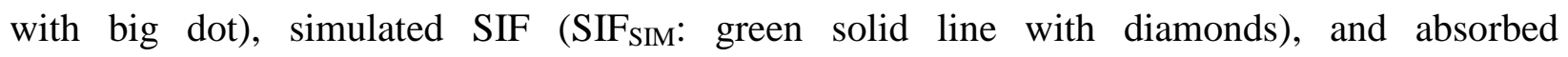
phtosynthetically active radiation (aPAR: red solid line with triangles) within $5^{\circ}$ latitudinal band are shown. The CCDAS set up S4 (Table 3) is considered. The period of June 2009 and December 2010 period is considered. 


\section{Simulations of Zhang et al. (2014) with SCOPE v1.53}

To understand the differences between our results and those from Zhang et al. (2014), we carefully made detailed analysis by using the SCOPE model alone and SCOPE settings reported in Zhang et al. (2014). For the environmental input (temperature and short wave radiation), we used their values over a large range. Then, we made simulations of SIF at ecosystem by using the C4 crop (here corn) and C3 plant (soybean) with SIF retrieved at the frequency $740 \mathrm{~nm}$. The tests are carried out by using the SCOPE model alone with the fluorescence model choice 0 (i.e., empirical fit to the data of Flexas et al. (2002); version 1.53). In details, the more relevant settings of SCOPE we used can be described as follows. The radiation varies from 1 to 1200 $\mathrm{W} / \mathrm{m}^{2}$. The $\mathrm{V}_{\text {cmax }}$ varies from 1 to $350 \mu \mathrm{mol} \mathrm{m} \mathrm{m}^{-2} \mathrm{~s}^{-1}$. The temperature varies from $10^{\circ} \mathrm{C}$ to $30^{\circ} \mathrm{C}$. $\mathrm{C}_{\mathrm{ab}}$ values from 1 to $80 \mu \mathrm{g} \mathrm{cm}^{-2}$ are used. Several values of LAI (between 0.1 and 6) are used. The strongest sensitivity for SIF was found for a temperature input of $28^{\circ} \mathrm{C}$, a LAI of 6 (Fig. S11). This optimal simulation sensitivity does not reach the magnitude seen in Zhang et al. (2014). Using these inputs, SIF almost double between $V_{c \max }$ values of 10 and 200, whereas Zhang et al. (2014) sees SIF increases by a factor greater than three (See Figure 3 in Zhang et al., 2014). Again, with the current version of SCOPE we are using, we do not find such a strong sensitivity of SIF to $V_{c \max }$ as obtained from Zhang et al. (2014). Our results do show a weak sensitivity of SIF to $\mathrm{V}_{\mathrm{cmax}}$ under low light condition and this sensitivity increases with the increase of the incoming short wave radiation when, but only for a rapid increase of $\mathrm{V}_{\text {cmax }}$ (e.g., between 10 and $75 \mu \mathrm{mol} \mathrm{m}^{-2} \mathrm{~s}^{-1}$ ) relative to growing period of the studied crops (Fig. S11).

The sensitivities of SIF to both $\mathrm{C}_{\mathrm{ab}}$ and LAI are also shown in Fig. S11. As expected, results clearly show the large sensitivity of SIF to these parameters. 


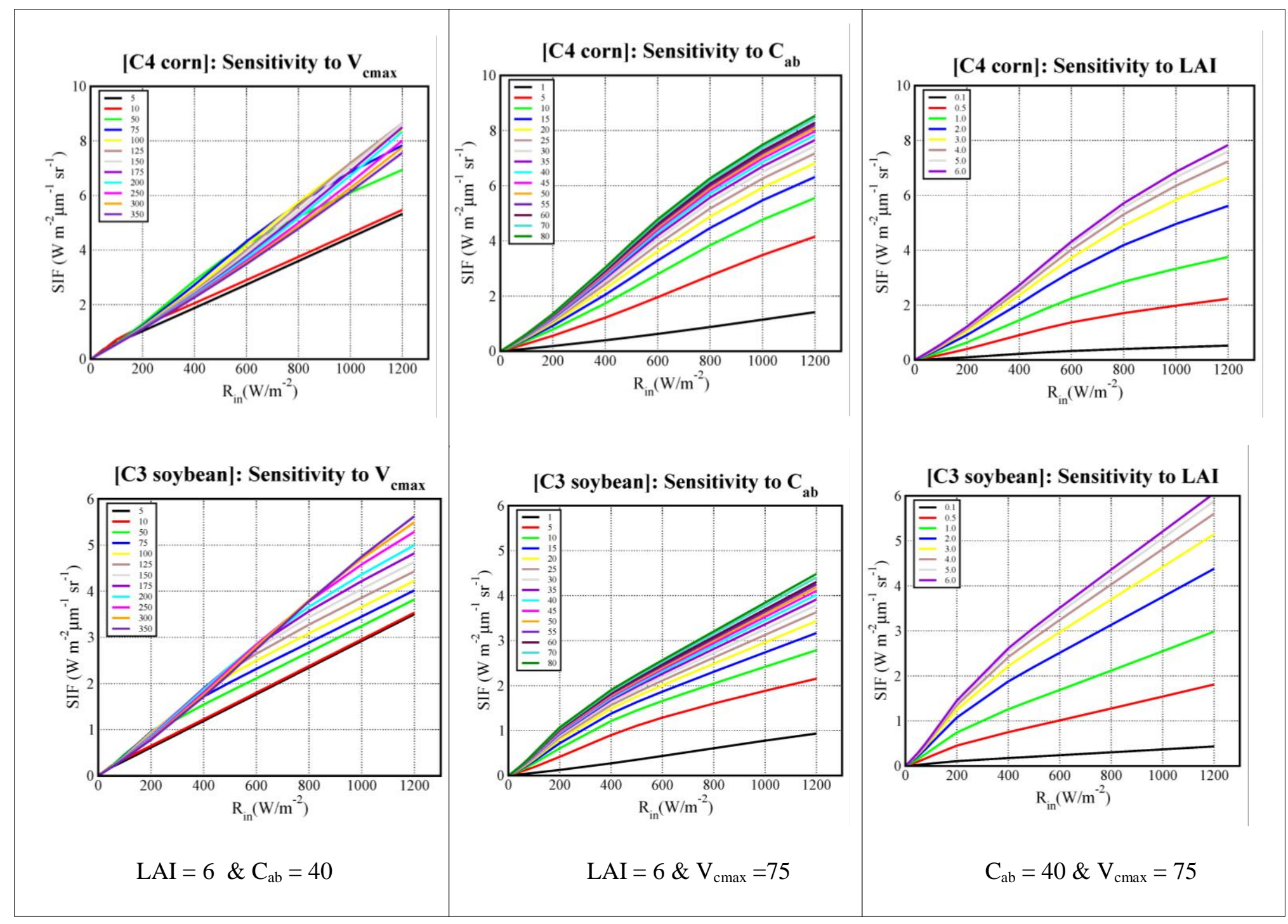

Fig. S11: Sensitivity of SIF to $\mathrm{V}_{\mathrm{cmax}}, \mathrm{C}_{\mathrm{ab}}$, and LAI as a function of the incoming short wave radiation $\mathrm{R}_{\mathrm{in}}$. SIF is computed at the frequency $740 \mathrm{~nm}$. The other SCOPE parameters are given in Table 1 of the paper. The Ball-Berry stomatal conductance parameter $\mathrm{m}$ in SCOPE model is set to 4 for corn (C4 plant) and 9 for soybean (C3 plant), respectively. The temperature is set to $28^{\circ} \mathrm{C}$. 


\section{Acknowledgment}

We are grateful to both Timo Vesala and Dario Papale for providing FLUXNET data at the stations Hyytiala and Roccarespampani 1

\section{References}

Baldocchi, D. D. (2003), Assessing the eddy covariance technique for evaluating carbon dioxide exchange rates of ecosystems: past, present and future. Global Change Biology, 9, 479-492.

Flexas, J., J. M. Escalona, S. Evain, J. Gul'1as, I. Moya, C. B. Osmond, and H. Medrano (2002), Steady-state chlorophyll fluorescence (Fs) measurements as a tool to follow variations of net $\mathrm{CO} 2$ assimilation and stomatal conductance during water-stress in C3 plants, Physiol. Plant., 114(2), 231-240.

Papale D., Reichstein, M., Aubinet, M., Canfora, E., Bernhofer, C., Kutsch, W., Longdoz, B., Rambal, S., Valentini, R., Vesala, T., and Yakir, D.: Towards a standardized processing of Net Ecosystem Exchange measured with eddy covariance technique: algorithms and uncertainty estimation. Biogeosciences, 3, 571-583, 2006. 